\title{
Quantifying spatial and temporal patterns of flow intermittency using spatially contiguous runoff data
}

Songyan Yu (于松延) ${ }^{1^{*}}$, Nick R. Bond ${ }^{2}$, Stuart E. Bunn ${ }^{1}$, Zongxue Xu ${ }^{3,4}$, Mark J. Kennard ${ }^{1}$

1. Australian Rivers Institute and Griffith School of Environment, Griffith University, Nathan, Queensland 4111, Australia

2. Murray-Darling Freshwater Research Centre, La Trobe University, Wodonga, Victoria 3689, Australia

3. College of Water Sciences, Beijing Normal University, Beijing 100875, China

4. Joint Centre for Global Changes Studies, Beijing 100875, China

Key words: drought, intermittent flow, ephemeral, stream hydrology prediction, spatial distribution, temporal pattern.

\section{Abstract}

River channel drying caused by intermittent stream flow is a widely-recognized factor shaping stream ecosystems. There is a strong need to quantify the distribution of intermittent streams across catchments to inform management. However, observational gauge networks provide only point estimates of streamflow variation. Increasingly, this limitation is being overcome through the use of spatially contiguous estimates of the terrestrial water-balance, which can also assist in estimating runoff and streamflow at large-spatial scales. Here we proposed an approach to quantifying spatial and temporal variation in monthly flow intermittency throughout river networks in eastern Australia. We aggregated gridded $(5 \times 5 \mathrm{~km})$ monthly water-balance data with a hierarchically nested catchment dataset to simulate catchment runoff accumulation throughout river networks from 1900-2016. We also predicted zero flow duration for the entire river network by developing a robust predictive model relating measured zero flow duration (\% months) to environmental predictor variables (based 
on 43 stream gauges). We then combined these datasets by using the predicted zero flow duration from the regression model to determine appropriate 'zero' flow thresholds for the modelled discharge data, which varied spatially across the catchments examined. Finally, based on modelled discharge data and identified actual zero flow thresholds, we derived summary metrics describing flow intermittency across the catchment (mean flow duration and coefficient-of-variation in flow permanence from 1900-2016). We also classified the relative degree of flow intermittency annually to characterise temporal variation in flow intermittency. Results showed that the degree of flow intermittency varied substantially across streams in eastern Australia, ranging from perennial streams flowing permanently (11-12 months) to strongly intermittent streams flowing 4 months or less of year. Results also showed that the temporal extent of flow intermittency varied dramatically inter-annually from 1900-2016, with the proportion of intermittent (weakly and strongly intermittent) streams ranging in length from $3 \%$ to nearly $100 \%$ of the river network, but there was no evidence of an increasing trend towards flow intermittency over this period. Our approach to generating spatially explicit and catchment-wide estimates of streamflow intermittency can facilitate improved ecological understanding and management of intermittent streams in Australia and around the world.

\section{Introduction}

The ecology and management of perennial streams have long been a central focus of freshwater sciences, while intermittent and ephemeral streams have only seen recent research interests (Acuña et al., 2017; Datry et al., 2014; Leigh and Datry, 2017). Many contemporary ecosystem theories developed to explain how rivers function originated from research on temperate, perennial streams and their transferability to non-perennial streams is not well understood (Williams, 1988). Uncritical extrapolation of theories developed in permanent lotic ecosystems to intermittent or ephemeral streams can prove perilous or even misleading (Boulton and Suter, 1986). However, intermittent 
streams are extremely prevalent globally, potentially comprising at least $50 \%$ of the world's lotic freshwaters (Acuña et al., 2014; Datry et al., 2014; Leigh and Datry, 2017). Additionally, the number and length of intermittent streams are projected to increase in regions experiencing drying trends related to climate change and increases in water abstraction for socio-economic uses (Datry et al., 2011; Larned et al., 2010) which are altering river flow regimes and hydrologic connectivity (Döll and Zhang, 2010; Jaeger et al., 2014).

Improved understanding of temporal and spatial patterns in flow intermittency is fundamentally important for effective river management (Snelder et al., 2013). However, this has been impeded by the scarcity of information about the distribution and hydrologic characteristics of intermittent streams (Acuña et al., 2017; Datry et al., 2011; Nadeau et al., 2015). This has resulted in increased research focus on quantifying the distribution of intermittent streams in particular geographic regions, such as France (Snelder et al., 2013), Australia (Kennard et al., 2010b), Spain and North America (de Vries et al., 2015). A key shortcoming of these studies, however, is that they are largely restricted to analysis of data from particular stream gauge locations, rather than using spatially contiguous flow data. This has made it difficult to effectively communicate the essential spatial relationships of complex hydrologic systems (Turner and Richter, 2011). For example, the gauging station network likely under-represents the intermittent river segments, such as in France where $19.6 \%$ of gauges were classified as intermittent whereas $39 \%$ of segments in the river network are predicted to be intermittent (Snelder et al., 2013).

Alternative methods of identifying intermittent streams include the use of electrical arrays by measuring electrical conductivity of the streambed (Jaeger and Olden, 2012), citizen-observation networks supported by regular reports from trained volunteers (Datry et al., 2016; Turner and Richter, 2011), deployment of unmanned aerial system (Spence and Mengistu, 2016), modelling stream flows for ungauged catchments (Young, 2006) and developing predictive models for intermittent streams (González-Ferreras and Barquín, 2017). Nevertheless, shortcomings still exist in these methods. Electrical arrays alone are only able to determine absence/presence of water and 
cannot provide quantitative stream discharge estimates, and can also provide false positives due to retained moisture in pools. The mapping accuracy by citizen-observation methods is limited by subjectivity of interpretation and the frequency of site visits, and observations can be interrupted by unexpected reasons such as extreme bad weather events and sickness. The utility of unmanned aerial system is often impaired by riparian tree canopy (Turner and Richter, 2011) and may take more time than would have been required to conduct ground-based surveys of the intermittent stream, let alone the office labour time analysing high-resolution images (Spence and Mengistu, 2016). Most models have serious limitations in accurately simulating hydrological extremes, including low flow events that may lead to zero flows (Costigan et al. 2017). Predictive models only tell the static distribution of intermittent streams rather than their temporal dynamics.

The ideal hydrologic data required for quantifying geographic and temporal variation in flow intermittency is continuously-measured streamflow data gauged at every point of river channel, however this is unrealistic. Instead, researchers are increasingly utilising widely available climate and other environmental datasets to develop hydrologic models to provide equivalent data. Recently, a water balance model (WaterDyn) has been developed to model the terrestrial water balance across Australia and to provide gridded monthly water balance data at the national scale (the Australian Water Availability Project - AWAP) (Raupach et al., 2008; 2009). Key inputs and constraints on the model are the meteorology data (solar radiation, precipitation, minimum and maximum daily temperature) and other environmental characteristics (e.g. albedo, soil characteristics, seasonality of vegetation greenness), most of which comprise a century-plus time series from the beginning of 1900 to the end of the latest year. The model yields spatially contiguous monthly water availability values gridded at a spatial resolution of $5 \mathrm{~km}$. The development of such water balance models in Australia as well as other parts of the world provides the potentials to overcome the limitation of point-estimates of discharge data. The more than one century (1900-2016) record of the Australian terrestrial water balance simulated by the WaterDyn model offers a promising opportunity to identify both the spatial and temporal patterns of flow intermittency. A key limitation of the gridded 
runoff output from the model is that it cannot be used directly to identify flow intermittency in streams and rivers as it requires conversion to discharge data along river networks, by accumulating runoff down catchments. Developing such a conversion process requires a combination of the gridded runoff with a hierarchically nested catchment framework. In addition, due to the potential uncertainty in the ability of water-balance models to predict low flows (Costelloe et al., 2005; Ivkovic et al., 2014; Ye et al., 1997), causing over-estimation of the magnitude of low flows in this case, estimation of an appropriate zero flow threshold was necessary for each stream segment. The modelled discharge data may require truncation by the identified zero flow thresholds to accurately reflect cease to flow dynamics. This truncation will likely vary across catchments based on stream size, and is best estimated empirically by comparison with observed flow data.

In this study, we developed a new method based on the AWAP WaterDyn model to identify the spatial extent and temporal patterns of flow intermittency using spatially contiguous flow data. This method was designed to overcome the aforementioned limitations by making the conversion process effective and efficient and identifying appropriate zero flow thresholds for modelled discharge data. This research presents an innovative approach that could provide insights into two key issues confronting intermittent stream management identified by Acuña et al. (2017): 1) the scarcity of information on the spatial extent of intermittent streams; 2) the potential shift of perennial streams to intermittent streams due to climate change and intense human activities.

\section{Methodology}

\subsection{Stream and catchment framework}

The hierarchically nested catchment dataset used in this study was sourced from the Australian Hydrological Geospatial Fabric (Geofabric) (Stein et al., 2014) which provides a fully connected and directed stream network and associated catchment hierarchy. We used the directed stream network and associated catchment boundaries (i.e. AHGF Catchment boundaries, Fig. 1) as well as accompanying environmental data (Table. 1) (Stein et al., 2014). 


\subsection{Study area}

This research was conducted in five major coastal river basins of south-eastern Queensland (SEQ), Australia, comprising an area of $21,331 \mathrm{~km}^{2}$ (Fig. 1) (Australian Bureau of Meteorology, 2014) and home to $72 \%$ of Queensland's population (Australian Bureau of Statistics, 2011). SEQ has 7,229 stream segments and their corresponding sub-catchments in the Geofabric out of 1.4 million for Australia. SEQ is a region of transitional temperate to subtropical climate with substantial inter- and intra-annual variation in discharge. Usually the majority of rainfall and streamflow occur in the summer months of January to March, often followed by a second minor discharge peak between April and June, but high and low flows may occur at any time of year (Kennard et al., 2007). Thus, there are a range of flow regimes with many streams being intermittent to varying degrees. Kennard et al. (2010b) identified three major flow regime types in SEQ coastal streams and rivers: Class 4 (unpredictable baseflow), Class 7 (unpredictable intermittent) and Class 11 (unpredictable summer highly intermittent). Each major catchment was further divided into sub-catchments using the Geofabric (Fig. 1(b)).

Fig. 1 Geofabric river network and catchments in south-eastern Queensland and the locations of 43 selected gauges within SEQ. Inset (a) shows the relative location of SEQ in Australia and inset (b) indicates Geofabric stream segments and associated sub-catchments.

\subsection{Gauged streamflow data}

Mean daily discharge data for 43 stream gauges were used in the analyses (Fig. 1 and Table A.1). The gauges were widely dispersed throughout the study area and encompassed a range of stream sizes and flow regime types. These included the 30 gauges used in Kennard et al. (2010b) plus an additional 13 gauges acquired from Bureau of Meteorology (http://www.bom.gov.au/waterdata/) that met the following criteria: (1) little or no hydrologic modification due to human activities; (2) a period of hydrologic record $\geq 15$ years; (3) $\leq 10 \%$ missing mean monthly discharge data. Criterion 1 
was assessed using the River Disturbance Index (RDI) (Stein et al., 2002). This index was computed based on flow regime disturbance caused by impoundments, flow diversions and levee banks, and catchment disturbance due to urbanisation, road infrastructure and land use activities. Criterion 2 was based on the conclusion of Kennard et al. (2010a) that 15 years of discharge record is suitable for use in hydrologic metric estimation. For each gauge, we converted daily discharge data $\left(10^{3} \mathrm{~m}^{3} /\right.$ day) to mean daily discharge per month $\left(10^{3} \mathrm{~m}^{3} /\right.$ month) and calculated the percentage of months with zero flow across the entire record. This summary metric was used as the response variable in the subsequent regression analyses (Fig. 2). Uncertainty exists in the measurement of discharge by stream gauging, especially at very low flows (Kennard et al., 2010a), as gauging stations are not normally well-calibrated to measure zero flows and small changes due to erosion/deposition of sediments in the gauging section can modify the estimate of zero flow (Gallart et al., 2017). We therefore defined the threshold of flowing water as $0.110^{3} \mathrm{~m}^{3} /$ day (McJannet et al., 2014). Preliminary analyses using different zero flow thresholds (i.e. $0,0.1,1,2$, and $310^{3} \mathrm{~m}^{3} /$ day, respectively) revealed very little difference in the percentage of time with zero flows for the entire record.

\subsection{Environmental variables}

Numerous environmental variables have the potential to influence spatial variation in zero flow duration. For instance, Snelder et al. (2013) used a random forest model to assess the degree to which flow intermittency was related to different environmental variables based on 628 gauges across France. They found eight out of 15 selected environmental variables (including climatic and catchment variables) were significant predictors of flow intermittency.

Guided by previous studies, we used 13 environmental variables as candidate predictors of spatial variation in zero flow duration (Table 1, Fig. 2). These included the following five climatic parameters calculated for the catchment upstream of each gauging station: average annual precipitation (Aver_annual_Precip), average annual total evaporation (Aver_annual_FWE), average annual daily 
maximum temperature (Aver_annual_TempMax) and average annual daily minimum temperature (Aver_annual_TempMin) and catchment average annual mean temperature (CATANNTEMP). The first four parameters were calculated in the same way by averaging gridded monthly climatic data (source: AWAP) for the catchment upstream of stream gauge across the total record. The last parameter as well as the following parameters were obtained from the Geofabric datasets (Stein et al., 2014). Additional variables included catchment-scale parameters, including catchment area (CatArea), catchment shape (Elongation ratio; Shape), catchment average slope (Slope), catchment average elevation (Elev), catchment storage (CATSTORAGE), catchment maximum elevation (CATELEMAX), catchment average saturated hydraulic conductivity (CAT_A_KAST) and stream density (STRDENSITY). All environmental variables were calculated for the catchment upstream of the gauging station.

Table 1. Environmental predictor variables included in the regression analyses.

\subsection{Converting simulated runoff data to spatially contiguous discharge data}

The simulated runoff data from the water balance model was downloaded from outputs of the AWAP WaterDyn model (http://www.csiro.au/awap/) (Fig. 2). These data are in gridded format and required conversion to stream flow for each sub-catchment by aggregating the gridded runoff data with a hierarchically nested catchment to simulate discharge throughout river networks. This conversion process was undertaken using the catchstats package in $\mathrm{R}$, but with modification of two functions (see Table 2) into parallel processing versions to speed up the calculation process. There are four functions applied in the conversion process (Table 2). The principle of the conversion process is that firstly gridded runoff output from the AWAP WaterDyn model is superimposed on the Geofabric catchment layer to extract runoff for each sub-catchment, using spatially-weighted averages when a sub-catchment bisects grid boundaries, then modelled discharge data are 
calculated by multiplying the extracted runoff by the corresponding sub-catchment area. Finally, for any given sub-catchment, modelled discharge of all of its upstream sub-catchments are summed and used as its discharge (Fig. 2). We did not apply any lagged streamflow routing equations because a monthly time step is likely sufficient to integrate over any lags in flow peaks in these catchments (Raupach et al., 2009).The catchstats package includes a set of functions for downloading the AWAP data and conditions of these processing steps and is available from github (www.github.com/nickbond/catchstats). All of the conversion process were run on a DELL Rack Server with 24 cores and RAM 32GB.

Table 2. Names and descriptions of the four functions in the package "catchstats" that were used in the conversion process. Bold functions are ones that have been updated into a parallel processing version.

\subsection{Regression analyses to predict zero flow duration}

Due to potential uncertainty in the ability of water-balance models to predict low flows, causing over-estimation of the magnitude of low flows in this case, estimation of an appropriate zero flow threshold was necessary for each stream segment. Regression modelling that related catchment environmental attributes to measured zero flow duration at gauged locations was used to predict zero flow duration for the entire river network and thus enable determination of the appropriate 'zero' flow thresholds for the modelled discharge in each river segment (Fig. 2). Zero flow values for modelled discharge at each stream segment were estimated by using the regression model to predict zero flow duration, and then identifying the low flow threshold in the modelled discharge with the equivalent flow duration. Flows below this threshold were then converted to zero.

Before regression analyses, we visually checked the normality of all environmental predictor variables and transformed $(\log (x+1))$ those that were not normally distributed as some variables 
have zero values. Six variables, including Aver_annual_Precip, Aver_annual_TempMin, CatArea, Shape, Slope and CATSTORAGE, were identified as having skewed distributions and were logtransformed (referred to as Log_Aver_annual_Precip, Log_Aver_annual_TempMin, Log_CatArea, Log_Shape, Log_Slope and Log_CATSTORAGE). Log_Aver_annual_Precip and Log_CATSTORAGE could not be normalised and were thus excluded from subsequent analyses.

Regression models were developed using all possible predictor variable combinations and we selected the 'best' model for predicting zero flow duration based on corrected Akaike's Information Criterion (AICC) (Hurvich and Tsai, 1989). To estimate the prediction error of the selected model, we repeated leave-one-out cross validation on the selected 43 gauges and reported prediction error $\left(R^{2}\right)$ to estimate the model prediction performance. Regression model development and cross-validation were conducted with the MuMIn and boot packages in R (R Development, 2012).

\subsection{Accuracy assessment of modelled discharge}

We evaluated the accuracy of the modelled discharge by comparing it to the measured discharge at 43 gauges using the Nash-Sutcliffe model efficiency coefficient (NS) (Nash and Sutcliffe, 1970), which has been commonly used as efficiency criteria for hydrological models (Krause et al., 2005). To further evaluate model accuracy on zero flow estimation, we also compared the different aspects of zero flow regimes, including the frequency and mean duration of zero flow periods as well as the mean timing (month of year) of zero flows between the modelled and measured discharge. The frequency of zero flow periods was calculated as the total number of discrete zero flow periods (minimum length of one month) across the entire record. The mean duration of zero flow periods was calculated as the average length (number of months) zero flow periods across the entire record. The mean timing of zero flows was calculated using circular statistics (Bayliss and Jones 1993) as the average month of the year in which zero flows occurred across the entire record.

\subsection{Quantifying spatial and temporal patterns of flow intermittency}


Using the modelled discharge, we calculated the mean number of months per year with zero flow for each stream segment, and then quantified the spatial extent of flow intermittency (Fig. 2). The coefficient of variation of flow intermittency were also presented to indicate its intra-annual variation.

The frequency and duration of zero-flow events are hydrologic metrics widely used to characterise low flow hydrology and classify streams based on their degree of intermittency (Knighton and Nanson, 2001; Larned et al., 2010; Snelder et al., 2013). Guided by Hewlett (1982), we defined perennial streams as those that ceased flowing $<10 \%$ of the year ( 0 - 1 months), weakly intermittent as those that ceased flowing $10-70 \%$ of the year ( $2-8$ months), and strongly intermittent as those that ceased flowing $>70 \%$ of the year ( $>8$ months) (Fig. 2). The temporal pattern of intermittent streams in SEQ was derived by using these thresholds to classify modelled discharge for each stream segment for each year of the record of 1900-2016.

Fig. 2 Flow diagram of analysis. We collected or calculated 13 candidate environmental predictor variables from AWAP or Geofabric datasets, and calculated zero flow duration (\% of months with zero flow) with stream flow data from selected 43 gauge stations across SEQ. We developed a predictive model relating zero flow duration to environmental predictor variables and then predicted zero flow duration for all stream segments based on spatial data of the predictor variables. We aggregated gridded monthly runoff data with a hierarchically nested catchment dataset to simulate discharge throughout river networks from 1900 to 2016. We then used the predicted zero flow duration from the regression model to estimate 'zero' flow thresholds in the modelled discharge data at all stream segments by assuming that each stream segment has the same zero flow duration as predicted. Finally, based on modelled discharge data and identified actual zero flow thresholds, we calculated the mean number of months per year with zero flow across 1900-2016 to identify the spatial extent of flow intermittency in south-eastern Queensland (SEQ). We also 
classified flow intermittency annually for all streams in SEQ to quantify the temporal patterns of flow intermittency.

\section{Results}

\subsection{Regression analyses}

Regression analyses were performed on all combinations of predictor variables and returned the least-AICc (-54.2) predictive model with 5 covariates, including Aver_annual_TempMax, Log_CatArea, Log_Slope, Elev and CAT_A_KAST. The developed predictive model showed a good model fit with an adjusted $R^{2}$ of 0.71 (Table 3 and Fig. 3), and the leave-one-out cross validation on the regression model showed relatively good model performance with an average $R^{2}$ of 0.64 .

Table 3. Results of the 'best' regression model in which the percentage of months with zero flows was modelled as a function of environmental covariates shown in the first column. The standardised model coefficients and the estimated P-values for each regression parameter are also shown.

Fig. 3 Predicted vs. measured percentage of months without flows. The solid line represents the function of $y=x$.

\subsection{Accuracy of modelled discharge data}

Converting the simulated runoff data from the water balance model to spatially contiguous monthly discharge data and truncating low flows by the predicted zero flow threshold for each stream segment using the regression model, yielded a continuous monthly time series of modelled discharge data for all stream segments in the study area. The model accuracy was evaluated by the comparison between measured and modelled discharge for 43 gauges, which suggested a good of fit for the majority of gauges with the median value of Nash-Sutcliffe coefficient (NS) of 0.79 , but 
extreme low NS coefficients were evident for three gauges: -0.79 for gauge $143213,-1.44$ for gauge 143232, and -2.36 for gauge 146014 (Fig. 4) (see Discussion section).

Fig. 4 Scatter plots of the relationship between measured and modelled (truncated) discharge for each gauge station, arranged in order of increasing percentage of months of zero flow. The percentage of months of zero flow and Nash-Sutcliffe coefficient are presented in each panel as "\%D" and "NS", respectively. The $\mathrm{x}$ and $\mathrm{y}$ axes are log transformed (i.e. $\log 10(\mathrm{x}+1)$ ) for better interpretation.

Assessment of model accuracy for estimating of the frequency, duration and timing of zero flows revealed generally good concordance with measured data (Fig. 5). The modelled frequency of zero flow periods generally aligned well with the measured $\left(R^{2}=0.63\right)$, except for six gauges showing significant overestimation (Fig. 5(a)). This also was the case for the mean duration $\left(R^{2}=0.62\right)$, which showed that for the majority of gauges the modelled mean durations were similar to the measured, but six gauges were well overestimated in mean duration (Fig. 5(b)). For both zero flow measures, most of the outlier gauges had a high percentage of months with zero flows. The modelled timing of zero flow periods showed a poorer overall concordance with measured data $\left(R^{2}=-0.03\right)$, with six outlier gauges that had at least three-month differences (Fig. 5(c)). These outliers tended to have a very low percentage of zero flow months.

Fig. 5 Scatter plot of the relationships between measured and modelled frequency of zero flow periods (a), between measured and modelled mean duration of zero flow periods (b) and between measured and modelled mean month of zero flows (c). Outlier dots on all panels are presented with gauge number and its associated percent of months without flows in parentheses. The solid and 
dashed lines represent the function of $y=x$ and the regression line. $R^{2}$ value is also presented with the regression line.

\subsection{Spatial extent of flow intermittency across SEQ}

The degree of flow intermittency varied substantially across streams within SEQ, ranging from perennial streams flowing permanently (11-12 months) to strongly intermittent streams flowing 4 months or less of year (Fig. 6(a)). The majority of coastal streams and the main stems of major rivers were perennial, while most inland headwaters were weakly to strongly intermittent, particularly in the southwestern part of the Brisbane River catchment. This spatial pattern is reasonable because coastal areas in SEQ tend to have more precipitation than inland areas and mainstreams usually have larger drainage areas than headwaters.

Higher coefficients of variation of flow intermittency tended to occur in the perennial larger main stem rivers and coastal streams, while smaller inland intermittent streams showed lower coefficients of variation (Fig. $6(\mathrm{~b}))$, suggesting that though mainstreams and coastal streams flowed permanently on average, they sometimes had long period of zero flows during extreme droughts, and streams that usually flow intermittently tended to remain in this state from year to year.

Fig. 6. The spatial extent of flow intermittency presented by (a) mean zero flow duration per year across 1900-2016 and (b) its coefficient of variation (CV).

\subsection{Temporal pattern of intermittent streams across SEQ}

The temporal extent of flow intermittency varied dramatically inter-annually from 1900-2016, with the proportion of intermittent (weakly and strongly intermittent) streams ranging in length from $3 \%$ to nearly $100 \%$ of the river network. Four intense drought periods that occurred in Australia over the 
study period were well-reflected in the temporal patterns of flow intermittency (Fig. 7), but there was no evidence of an increasing trend towards flow intermittency over this period. The distribution of intermittent streams in typical years (Fig. 7), demonstrated substantial variation in flow intermittency in time and space. In the driest year of $1902,99 \%$ of streams and rivers were classified as intermittent; mainstreams and coastal streams had less flow intermittency than headwaters and inland rivers. In the average (median) year of 1985, Almost half of streams (i.e. 47\%) were classified to intermittent streams, which were mainly inland headwaters receiving less precipitation than coastal streams; mainstreams and coastal streams remained constantly flowing in normal years. In the wettest year of 1950, very few streams flowed intermittently.

Fig. 7 The inter-annual variation of the proportion of intermittent (weakly and strongly intermittent) streams in length across SEQ. Four significant droughts in Australia were also presented as dotted rectangle, of which the width denote the duration of the drought. Insets demonstrated the specific distribution of intermittent streams in the driest year of 1902 (a), the average (median) year of 1986 (b) and the wettest year of 1950 (c) during the period of 1900-2016, respectively. Streams are colour-coded according to the classification of flow intermittency: perennial (blue) = cease flowing $<10 \%$ of the year ( 0 - 1 months), weakly intermittent (yellow) = cease flowing $10-70 \%$ of the year $(2-$ 8 months), strongly intermittent $($ red $)=$ cease flowing $>70 \%$ of the year ( $>8$ months).

\section{Discussion}

With growing calls to recognize the ecological importance of intermittent streams (Datry et al., 2014), the scarcity of information on the spatial and temporal extent of flow intermittency has been identified as a major barrier for ecologists and managers seeking to understand and protect these ecosystems (Acuña et al., 2017). The ability to overcome this barrier is increasing with advancing Geographic Information Systems technologies and spatially contiguous datasets becoming more 
readily available. In this study, we proposed a new method for quantifying the spatial extent of intermittent streams within catchments on an inter-annual basis. Our results not only provide the spatial distribution of intermittent flow, but also reveal the temporal dynamics of intermittent streams over long time-frames.

In the proposed method, the AWAP WaterDyn model of monthly runoff was used to quantify flow intermittency in south-eastern Queensland coast streams. The use of monthly data does not require conversion of application of lagged streamflow routing equations to convert runoff to discharge and the monthly time-step is suitable for quantifying ecologically relevant spatial and temporal variation in streamflow intermittency over large scales (i.e. throughout entire river networks across multiple river basins) and over long time frames (> 100 years). Nonetheless, monthly discharge data may be insufficient for studies aimed at quantifying ecological responses to short term flow events (e.g. high and low flows), where discharge data of a finer temporal grain may be required. In this case, daily gridded runoff coupled with lagged river routing equations could be considered (e.g. David et al., 2011b). For example, in Australia a daily gridded distributed water balance model (AWRA-L model, Viney et al., 2015), has been developed at the national scale to model the flow of water through landscape, while a river routing model (RAPID, David et al., 2011a; David et al., 2011b) has also been established to operate on gridded land surface model. However, significant methodological and technical challenges remain in accurately quantifying low flows at a daily time step due to difficulties in representing flow-pulse recession rates and how this influences low flow spell characteristics (e.g. magnitude, duration, frequency, timing).

\subsection{Accuracy of modelled discharge data}

Modelled discharge data were in good alignment with the measured, but extreme low Nash-Sutcliffe coefficient values happened for three gauges (Fig. 4). Gauge 146014 (NS=-2.36) is located on a headwater stream and its stream flow tended to be overestimated by the AWAP model during the 
period of record, indicating that there might be continuous water extraction activity as it is surrounded by agriculture lands or recharging activity to groundwater occurring there. Gauge 143213 (NS=-0.79) and 143232 (NS=-1.44) both had very high zero flow duration ( $>73 \%$ of months) and short period of record (both 17 years), which undermined their NS evaluations since that the uncertainty in the ability of the water balance model to predict low flows.

Our tests of model accuracy suggested that the mean duration and frequency of zero flow periods can be represented appropriately by the AWAP WaterDyn model, except for streams that experienced extremely long periods of flow intermittency (Fig. 5). This suggests that the model is a generally robust model in simulating flows but still needs some improvement in simulating zero flows for strongly intermittent streams. The timing of zero flows was generally acceptably estimated by the model, except for streams that rarely ceased to flow.

There are two main caveats in the current version of the AWAP WaterDyn model. First, the model is not able to effectively account for the potential impacts of human activities on stream flow (Raupach et al., 2009), which may explain the poor performance of the model in runoff simulations in the low flow period when water extraction from rivers is expected, particularly in areas where high flow intermittency is driven by water extraction. In this situation, the model does not take the distribution of land uses into consideration but only uses remotely sensed vegetation greenness as proxy. The model is continuing to be updated and improved over time, and these two caveats could be mitigated or addressed by better treatment of different land uses and improvement of the observation model for vegetation greenness, which have already been on the further development list of the model (Raupach et al., 2009).

\subsection{Intermittent stream management}

The need to recognise the spatial extent of intermittent streams is an important first step to transiting better management of these important ecosystems (Acuña et al., 2017). An explicit spatial and temporal context such as is provided by spatially contiguous and long-term discharge data 
presented here should allow researchers to develop meaningful generalizations about the interaction between flow intermittency and ecology (Datry et al., 2014; Leigh and Datry, 2017; Sternberg and Kennard, 2013). Our results confirm that intermittent streams are prevalent throughout river networks in our study area. Our findings accord with previous estimations that around $50 \%$ of hydrologic gauges in Australia are considered intermittent (de Vries et al., 2015; Kennard et al., 2010b). This implies that attempts to manage rivers should proceed from recognising stream classification and applying appropriate principles, given that intermittent streams have significantly distinct characteristics from perennial streams. Researchers have proposed unique landscape approaches to advance intermittent stream ecology. For instance, Datry et al. (2016) proposed considering intermittent rivers as shifting mosaics of lotic (flowing water), lentic (standing water) and terrestrial (dry riverbed) habitats, and such a landscape perspective has a positive impact on understanding of biogeochemical processes and biodiversity patterns in intermittent rivers.

Apart from the scarcity of information on the spatial extent of intermittent streams, another concern about intermittent streams is the potential shift of current perennial streams to intermittent streams due to climate change and intense human activities, as it has been proven in several regions where the number of low-flow and non-flow days is increasing (King et al., 2015; Ruhí et al., 2016; Sabo, 2014). Our results suggest that the proportion of intermittent streams in length varied significantly during $1900-2016$, ranging from $3 \%$ to nearly $100 \%$ and different years show different spatial patterns of flow intermittency, however, they do not show a clear reduction in flow permanency over time. This may reflect the aseasonal rainfall patterns in this region, and uncertainty about the extent to which climate change will lead to rainfall reductions or increases in this region. Regardless, hindcasting to examine the range of historical variability in flow permanency may provide valuable insights into what degree of desiccation biota have experienced in the recent past. When combined with projections of flow intermittency response to global climate change, the temporal dynamics analysis could provide a means to estimate what impact climate change is likely to have on biotic persistence in these riverscapes. 


\subsection{Potential applications}

The approach presented here can be readily scaled up to the national scale. The two main data sources (i.e. the AWAP model and Geofabric) in this study are now accessible at the national scale, which means regression models relating the proportion of month of zero flows to environmental attributes could be developed and discharge data could be modelled across other areas (or indeed the entire continent). Additionally, the parallel processing versions of functions enhance this potential. The area of south-eastern Queensland is $21,331 \mathrm{~km}^{2}$, only $0.28 \%$ of the total Australian area. Assuming that computation time increases linearly with geographic area, the estimated time required to run the functions at the national scale would be 28 days on one processor, or about 3 days using the parallel processing versions of the functions, when running on 16 cores.

The approach can also be applied in other countries where suitable datasets exist. For example, there are similar national-scale hydrologic models to the AWAP model in Australia, such as the community Noah land surface model (Noah-MP) in the US (Niu et al., 2011), the Danish National Water Resources Model (Henriksen et al., 2003; Højberg et al., 2013), the SAFRAN_ISBA_MODCOU model for France (Habets et al., 2008), the HYPE model in SWEDEN (Bergstrand et al., 2014; Strömqvist et al., 2012), the LARSIM model in parts of Germany (Bremicker, 2000), the Grid to Grid model for the UK (Bell et al., 2009). In all these cases, they either produce river flow that can be directly applied or can be aggregated with a hierarchically nested catchment dataset to identify the spatial extent of intermittent streams. However, it is worth noting that most of the above hydrological models were constructed specially for high flow simulation (e.g. flood risks), which means that they might perform worse in low flow prediction (Habets et al., 2008). The correction for this biased performance presented in this study, identifying the equivalent values to zero in the modelled discharge data, could be used to deal with such an issue when applying the approach to other countries. 
Our results indicated the proportion of intermittent streams varied significantly in length over the 116 year study period, ranging from $3 \%$ to nearly $100 \%$ and different years show different spatial patterns of flow intermittency. This means that in the wettest year almost all streams keep flowing for at least eleven months, while in the driest period all stream segments could experience zero flows for at least one month. This finding not only suggests that SEQ is an area with highly variable flow regimes, but also further supports the view that intermittent streams are very common and underpins calls for more attention be paid to intermittent streams and their ecological importance at a landscape scale (Acuña et al., 2017; Datry et al., 2014; Leigh and Datry, 2017).

For example, spatial extent of flow intermittency, coupled with hydrologic connectivity metrics, such as the frequency and mean length of connected stream segments, could be used to estimate the temporal dynamics of lotic connectivity (Ward et al., 2002) and average patch connectivity (Datry et al., 2016) throughout the river network. Hydrologic connectivity is a widely recognized driver of freshwater ecosystem structure and function (Bunn et al., 2006; Jaeger et al., 2014; Larned et al., 2010) by facilitating the repeated recolonization of motile and drifting organisms from isolated stream pools to rewetted channel reaches (Magoulick and Kobza, 2003; Stanley et al., 1997). Therefore, analyses of temporal and spatial patterns in hydrologic connectivity could provide valuable insights into resistance and resilience research of aquatic ecosystems.

This research has provided a new method for quantifying the spatial and temporal extent of flow intermittency using spatially contiguous runoff data. We tested this innovative approach in eastern Australia and it showed that flow intermittency prevailed in the majority of streams but different periods during the past century had different degrees of flow intermittency. Given that more and more spatial terrestrial water-balance data are becoming readily available across Australia and around the world, similar analyses should be undertaken across a range of climate and catchment characteristics to enhance our understanding of the distribution of intermittent streams and the address concerns that perennial streams are shifting to intermittent streams in the Anthropocene. 


\section{Acknowledgement}

This research was supported by the China Scholarship Council (No. 201506040057), the Office of Water Science within the Australian Government Department of the Environment and Energy, and Griffith University. All authors contributed writing this paper and have no competing interests.

Appendix A.

Table 1. Basic information of 43 filtered gauge stations across SEQ. RDI denotes river disturbance index.

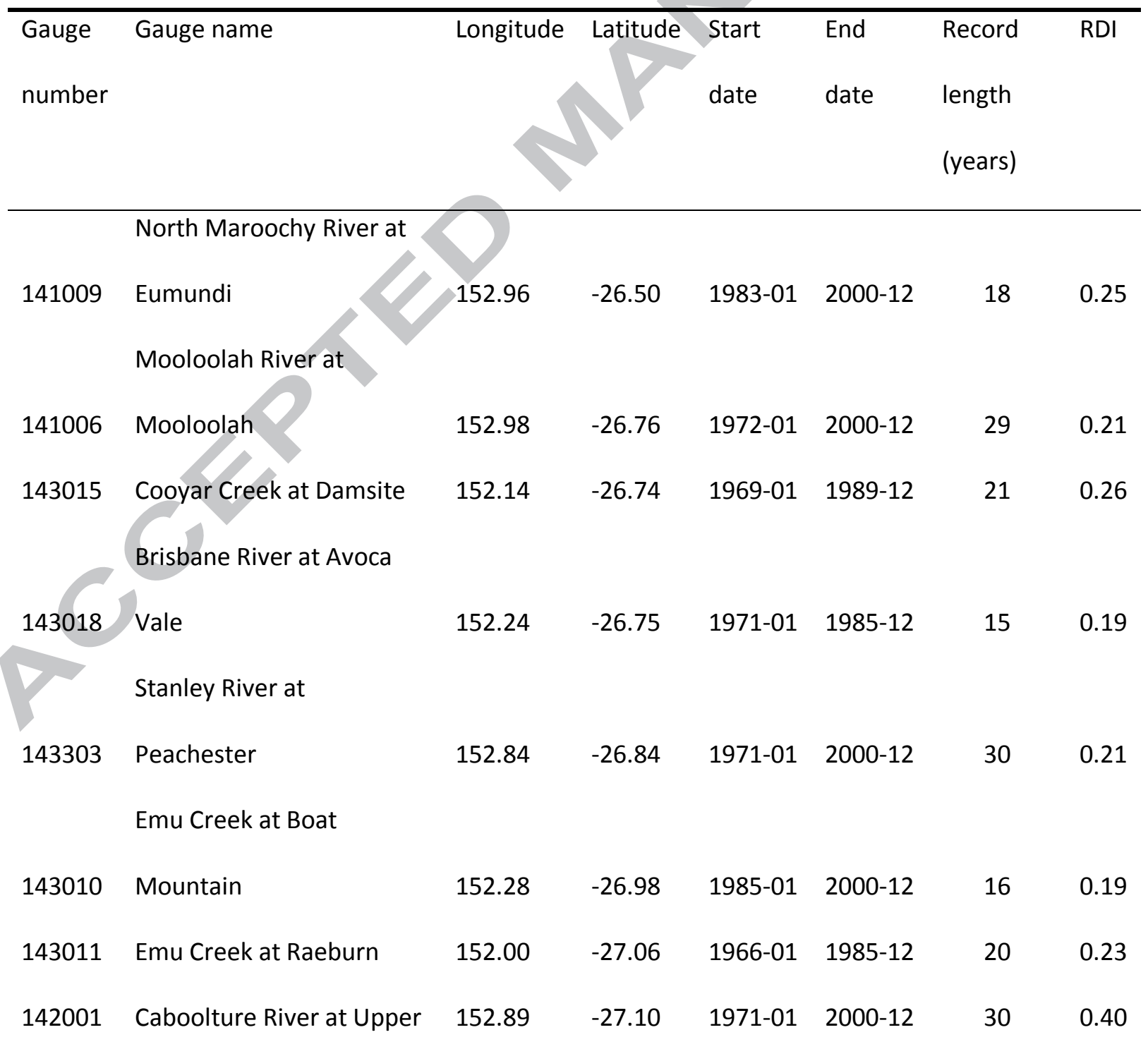


Caboolture

14330

Byron Creek at Causeway

1976-01 1998-12

23

0.05

Reedy Creek at Upstream

143306 Byron Creek Junction

152.64

$-27.13$

$1976-01 \quad 1998-12$

South Pine River at

142202 Drapers Crossing

152.92

$-27.35$

1966-01 1987-12

22

0.18

Fifteen Mile Creek at

143208 Damsite

$-27.46$

1965-01 1980-12

16

0.13

Lockyer Creek at Helidon

143203 No. 2

143107 Bremer River at Walloon

Bremer River at Adams

143110 Bridge

145102 Albert River at Bromfleet

Teviot Brook at The

145012 Overflow

Canungra Creek at Main

145107 Road Bridge

Coomera River at Army

146010 Camp

Logan River at Round

145008 Mountain

146014 Back Creek at Beechmont

145104 Canungra Creek at $32.2 \mathrm{~km}$

145101 Albert River at Kerry $\begin{array}{llllll}152.93 & -28.07 & 1971-01 & 2000-12 & 30 & 0.18\end{array}$

$\begin{array}{llllll}152.86 & -27.93 & 1971-01 & 2000-12 & 30 & 0.20\end{array}$

$\begin{array}{llllll}153.16 & -28.00 & 1974-01 & 2000-12 & 27 & 0.08\end{array}$

$\begin{array}{llllll}153.19 & -28.03 & 1971-01 & 2000-12 & 30 & 0.14\end{array}$

$\begin{array}{llllll}153.12 & -28.06 & 1965-01 & 1981-12 & 17 & 0.04\end{array}$

$\begin{array}{llllll}153.04 & -28.07 & 1971-01 & 2000-12 & 30 & 0.11\end{array}$ 
Cainbable Creek at Dam

\begin{tabular}{|c|c|c|c|c|c|c|}
\hline 145103 & Site & 153.08 & -28.09 & 1965-01 & 1993-12 & 29 \\
\hline \multirow[t]{2}{*}{145011} & Teviot Brook at Croftby & 152.57 & -28.15 & 1971-01 & $2000-12$ & 30 \\
\hline & Christmas Creek at Rudd & & & & & \\
\hline \multirow[t]{2}{*}{145013} & Lane & 152.98 & -28.17 & 1968-01 & $1987-12$ & \\
\hline & Currumbin Creek at & & & & & \\
\hline \multirow[t]{2}{*}{146003} & Camberra No. 2 & 153.41 & -28.20 & 1965-01 & $1982-12$ & 18 \\
\hline & Logan River at Forest & & & & & \\
\hline 5003 & Home & 152.77 & & & 0 & \\
\hline
\end{tabular}

Burnett Creek at

145018 Upstream Maroon Dam

152.61

$-28.22 \quad 1971-01 \quad 1999-12$

$29 \quad 0.04$

Running Creek at

145010 Deickmann Bridge

152.89

$-28.25$

$1971-01 \quad 2000-12$

30

0.23

Murphys Creek at Spring

143219 Bluff

151.99

$-27.47$

$1980-01 \quad 2012-12$

33

0.19

Flagstone Creek at Brown-

143233 Zirbels Road

143213 Ma Ma Creek at Harms

143212 Tenthill Creek at Tenthill

143232 Sandy Creek at Forest Hill

Moggill Creek at Upper

143032 Brookfield

152.89

$-27.49$

1977-01

2012-12

36

0.15

Ithaca Creek at Jason

143028 Street

152.99

$-27.45$

1973-01 2012-12

40

0.22

146020 Mudgeeraba Creek at

$\begin{array}{llll}153.35 & -28.09 & 1990-01 & 2012-12\end{array}$

0.11 
Springbrook Road

Logan River at

145020 Rathdowney

1974-01 2012-12

39

0.16

Brisbane River at Gregors

143009 Creek

152.41

$-26.99$

1963-01 2012-12

50

0.21

143113 Purga Creek at Loamside

$152.73 \quad-27.68$

1974-01 2012-12

$39 \quad 0.38$

Albert River at Beaudesert

145105

Pump Station

153.06

$-28.00$

1994-01 2011-12

18

0.15

Logan River at

145014 Yarrahappini

152.99

$-27.83 \quad 1970-01 \quad 2012-12$

43

0.23

\section{References}

Acuña, V. et al., 2014. Why should we care about temporary waterways? Science, 343(6175): 1080-1081.

Acuña, V., Hunter, M., Ruhí, A., 2017. Managing temporary streams and rivers as unique rather than second-

class ecosystems. Biological Conservation, 211(part B): 12-19.

Australian Bureau of Meteorology, National Water Account (2014),

http://www.bom.gov.au/water/nwa/2014/seq/contextual/physicalinformation.shtml. Data accessed in August of 2017.

Australian Bureau of Statistics 2011, Regional population growth, Australia 2012-13, viewed in August of 2017, www.abs.gov.au/AUSSTATS/abs@.nsf/DetailsPage/3218.02012-13.

Bayliss, A.C., Jones, R.C., 1993. Peaks-over-threshold flood database: Summary statistics and seasonality. Earth Surface Processes and Landforms, 19(7): 675-675.

Bell, V., Kay, A., Jones, R., Moore, R., Reynard, N., 2009. Use of soil data in a grid-based hydrological model to estimate spatial variation in changing flood risk across the UK. Journal of Hydrology, 377(3): 335-350. 
Bergstrand, M., Asp, S.-S., Lindström, G., 2014. Nationwide hydrological statistics for Sweden with high resolution using the hydrological model S-HYPE. Hydrology Research, 45(3): 349-356.

Boulton, A., Suter, P., 1986. Ecology of temporary streams-an Australian perspective, Limnology in Australia. CSIRO/Junk: Melbourne, pp. 13-327.

Bremicker, M., 2000. Das Wasserhaushaltsmodell LARSIM-Modellgrundlagen und Anwendungsbeispiele, Freiburger Schr. Hydrol.

Bunn, S.E., Thoms, M.C., Hamilton, S.K., Capon, S.J., 2006. Flow variability in dryland rivers: boom, bust and the bits in between. River Research and Applications, 22(2): 179-186.

Buttle, J. et al., 2012. An overview of temporary stream hydrology in Canada. Canadian Water Resources Journal, 37(4): 279-310.

Costelloe, J.F., Grayson, R.B., McMahon, T.A., 2005. Modelling stream flow for use in ecological studies in a large, arid zone river, central Australia. Hydrological processes, 19(6): 1165-1183.

Costigan, K., Kennard M. J., Leigh C., Sauquet E., Datry T. Boulton A. J., 2017. Flow regimes in intermittent rivers and ephemeral streams. In: T. Datry, N. Bonanda and A. J. Boulton, Intermittent rivers and ephemeral streams: ecology and management. London: Academic Press, pp. 51-78. ISBN 9780128039045.

Datry, T., Arscott, D.B., Sabater, S., 2011. Recent perspectives on temporary river ecology. Aquatic Sciences, 73(4): 453.

Datry, T., Larned, S.T., Tockner, K., 2014. Intermittent rivers: a challenge for freshwater ecology. BioScience, 64(3): 229-235.

Datry, T., Pella, H., Leigh, C., Bonada, N., Hugueny, B., 2016. A landscape approach to advance intermittent river ecology. Freshwater Biology, 61(8): 1200-1213.

David, C.H., Habets, F., Maidment, D.R., Yang, Z.-L., 2011a. RAPID applied to the SIM-France model. Hydrological Processes, 25(22): 3412-3425. DOI:10.1002/hyp.8070

David, C.H. et al., 2011b. River Network Routing on the NHDPlus Dataset. Journal of Hydrometeorology, 12(5): 913-934. DOI:10.1175/2011jhm1345.1de Vries, S.B. et al., 2015. Characterizing spatial and temporal patterns of intermittent rivers, EGU General Assembly Conference Abstracts.

Devito, K.J., Hill, A., Roulet, N., 1996. Groundwater-surface water interactions in headwater forested wetlands of the Canadian Shield. Journal of Hydrology, 181(1-4): 127-147. 
Döll, P., Zhang, J., 2010. Impact of climate change on freshwater ecosystems: a global-scale analysis of ecologically relevant river flow alterations. Hydrology and Earth System Sciences, 14(5): 783-799. DOI:10.5194/hess-14-783-2010

Gallart, F. et al., 2017. TREHS: An open-access software tool for investigating and evaluating temporary river regimes as a first step for their ecological status assessment. Sci Total Environ, 607-608: 519-540.

DOI:10.1016/j.scitotenv.2017.06.209

González-Ferreras, A.M., Barquín, J., 2017. Mapping the temporary and perennial character of whole river networks. Water Resources Research, 53(8): 6709-6724. DOI:10.1002/2017wr020390

Habets, F. et al., 2008. The SAFRAN-ISBA-MODCOU hydrometeorological model applied over France. Journal of Geophysical Research: Atmospheres, 113(D6).

Henriksen, H.J. et al., 2003. Methodology for construction, calibration and validation of a national hydrological model for Denmark. Journal of Hydrology, 280(1): 52-71.

Hewlett, J.D., 1982. Principles of forest hydrology. University of Georgia Press.

Højberg, A.L., Troldborg, L., Stisen, S., Christensen, B.B., Henriksen, H.J., 2013. Stakeholder driven update and improvement of a national water resources model. Environmental modelling \& software, 40: 202-213.

Hurvich, C.M., Tsai, C.-L., 1989. Regression and time series model selection in small samples. Biometrika: 297307.

Ivkovic, K., Croke, B., Kelly, R., 2014. Overcoming the challenges of using a rainfall-runoff model to estimate the impacts of groundwater extraction on low flows in an ephemeral stream. Hydrology Research, 45(1): 58-72. Jaeger, K.L., Olden, J.D., 2012. Electrical resistance sensor arrays as a means to quantify longitudinal connectivity of rivers. River Research and Applications, 28(10): 1843-1852.

Jaeger, K.L., Olden, J.D., Pelland, N.A., 2014. Climate change poised to threaten hydrologic connectivity and endemic fishes in dryland streams. Proceedings of the National Academy of Sciences, 111(38): 13894-13899. Jencso, K.G., McGlynn, B.L., 2011. Hierarchical controls on runoff generation: Topographically driven hydrologic connectivity, geology, and vegetation. Water Resources Research, 47(11). Kennard, M.J., Mackay, S.J., Pusey, B.J., Olden, J.D., Marsh, N., 2010a. Quantifying uncertainty in estimation of hydrologic metrics for ecohydrological studies. River Research and Applications, 26(2): 137-156. 
Kennard, M.J., Olden, J.D., Arthington, A.H., Pusey, B.J., Poff, N.L., 2007. Multiscale effects of flow regime and habitat and their interaction on fish assemblage structure in eastern Australia. Canadian Journal of Fisheries and Aquatic Sciences, 64(10): 1346-1359.

Kennard, M.J. et al., 2010b. Classification of natural flow regimes in Australia to support environmental flow management. Freshwater biology, 55(1): 171-193.

King, A.J., Townsend, S.A., Douglas, M.M., Kennard, M.J., 2015. Implications of water extraction on the lowflow hydrology and ecology of tropical savannah rivers: an appraisal for northern Australia. Freshwater Science, 34(2): 741-758.

Knighton, A.D., Nanson, G.C., 2001. An event-based approach to the hydrology of arid zone rivers in the Channel Country of Australia. Journal of Hydrology, 254(1): 102-123.

Konrad, C., 2006. Longitudinal hydraulic analysis of river-aquifer exchanges. Water resources research, 42(8). Krause, P., Boyle, D., Bäse, F., 2005. Comparison of different efficiency criteria for hydrological model assessment. Advances in Geosciences, 5: 89-97.

Larned, S.T., Datry, T., Arscott, D.B., Tockner, K., 2010. Emerging concepts in temporary-river ecology. Freshwater Biology, 55(4): 717-738.

Leigh, C., Datry, T., 2017. Drying as a primary hydrological determinant of biodiversity in river systems: A broad - scale analysis. Ecography, 40(4): 487-499.

Levick, L.R. et al., 2008. The ecological and hydrological significance of ephemeral and intermittent streams in the arid and semi-arid American southwest. US Environmental Protection Agency, Office of Research and Development.

Magoulick, D.D., Kobza, R.M., 2003. The role of refugia for fishes during drought: a review and synthesis.

Freshwater biology, 48(7): 1186-1198.

McJannet, D., Marvanek, S., Kinsey-Henderson, A., Petheram, C., Wallace, J., 2014. Persistence of in-stream waterholes in ephemeral rivers of tropical northern Australia and potential impacts of climate change. Marine and Freshwater Research, 65(12): 1131-1144.

Nadeau, T.-L. et al., 2015. Validation of rapid assessment methods to determine streamflow duration classes in the Pacific Northwest, USA. Environmental management, 56(1): 34-53. 
Nash, J.E., Sutcliffe, J.V., 1970. River flow forecasting through conceptual models part I-A discussion of principles. Journal of hydrology, 10(3): 282-290.

Niu, G.Y. et al., 2011. The community Noah land surface model with multiparameterization options (Noah - MP):

1. Model description and evaluation with local-scale measurements. Journal of Geophysical Research: Atmospheres, 116(D12).

R Development, C., 2012. TEAM 2009: R: A language and environment for statistical computing. Vienna, Austria. Internet: http://www. R-project. org.

Raupach, M. et al., 2009. Australian water availability project (AWAP): CSIRO marine and atmospheric research component: final report for phase 3. Centre for Australian weather and climate research (bureau of meteorology and CSIRO). Melbourne, Australia, 67.

Raupach, M. et al., 2012. Australian water availability project. Canberra: CSIRO Marine and Atmospheric Research.

Ruhí, A., Olden, J.D., Sabo, J.L., 2016. Declining streamflow induces collapse and replacement of native fish in the American Southwest. Frontiers in Ecology and the Environment, 14(9): 465-472.

Sabo, J.L., 2014. Predicting the river's blue line for fish conservation. Proceedings of the National Academy of Sciences, 111(38): 13686-13687.

Snelder, T.H. et al., 2013. Regionalization of patterns of flow intermittence from gauging station records. Hydrology and Earth System Sciences, 17(7): 2685-2699.

Spence, C., Mengistu, S., 2016. Deployment of an unmanned aerial system to assist in mapping an intermittent stream. Hydrological Processes, 30(3): 493-500.

Stanley, E.H., Fisher, S.G., Grimm, N.B., 1997. Ecosystem expansion and contraction in streams. BioScience, 47(7): 427-435.

Stein, J.L., Hutchinson, M., Stein, J., 2014. A new stream and nested catchment framework for Australia. Hydrology and Earth System Sciences, 18(5): 1917-1933.

Stein, J.L., Stein, J., Nix, H.A., 2002. Spatial analysis of anthropogenic river disturbance at regional and continental scales: identifying the wild rivers of Australia. Landscape and Urban Planning, 60(1): 1-25. Sternberg, D., Kennard, M.J., 2013. Environmental, spatial and phylogenetic determinants of fish life-history traits and functional composition of Australian rivers. Freshwater Biology, 58(9): 1767-1778. 
Strömqvist, J., Arheimer, B., Dahné, J., Donnelly, C., Lindström, G., 2012. Water and nutrient predictions in ungauged basins: set-up and evaluation of a model at the national scale. Hydrological Sciences Journal, 57(2): 229-247.

Turner, D.S., Richter, H.E., 2011. Wet/dry mapping: using citizen scientists to monitor the extent of perennial surface flow in dryland regions. Environmental management, 47(3): 497-505.

Viney, N. et al., 2015. AWRA-L v5.0: Technical description of model algorithms and inputs. CSIRO, Australia. Ward, J., Tockner, K., Arscott, D., Claret, C., 2002. Riverine landscape diversity. Freshwater Biology, 47(4): 517539.

Williams, W., 1988. Limnological imbalances: an antipodean viewpoint. Freshwater Biology, 20(3): 407-420. Winter, T.C., 2007. The role of ground water in generating streamflow in headwater areas and in maintaining base flow. JAWRA Journal of the American Water Resources Association, 43(1): 15-25.

Ye, W., Bates, B.C., Viney, N.R., Sivapalan, M., Jakeman, A.J., 1997. Performance of conceptual rainfall-runoff models in low-yielding ephemeral catchments. Water Resources Research, 33(1): 153-166.

DOI:10.1029/96wr02840

Young, A.R., 2006. Stream flow simulation within UK ungauged catchments using a daily rainfall-runoff model. Journal of Hydrology, 320(1): 155-172. DOI:https://doi.org/10.1016/j.jhydrol.2005.07.01 


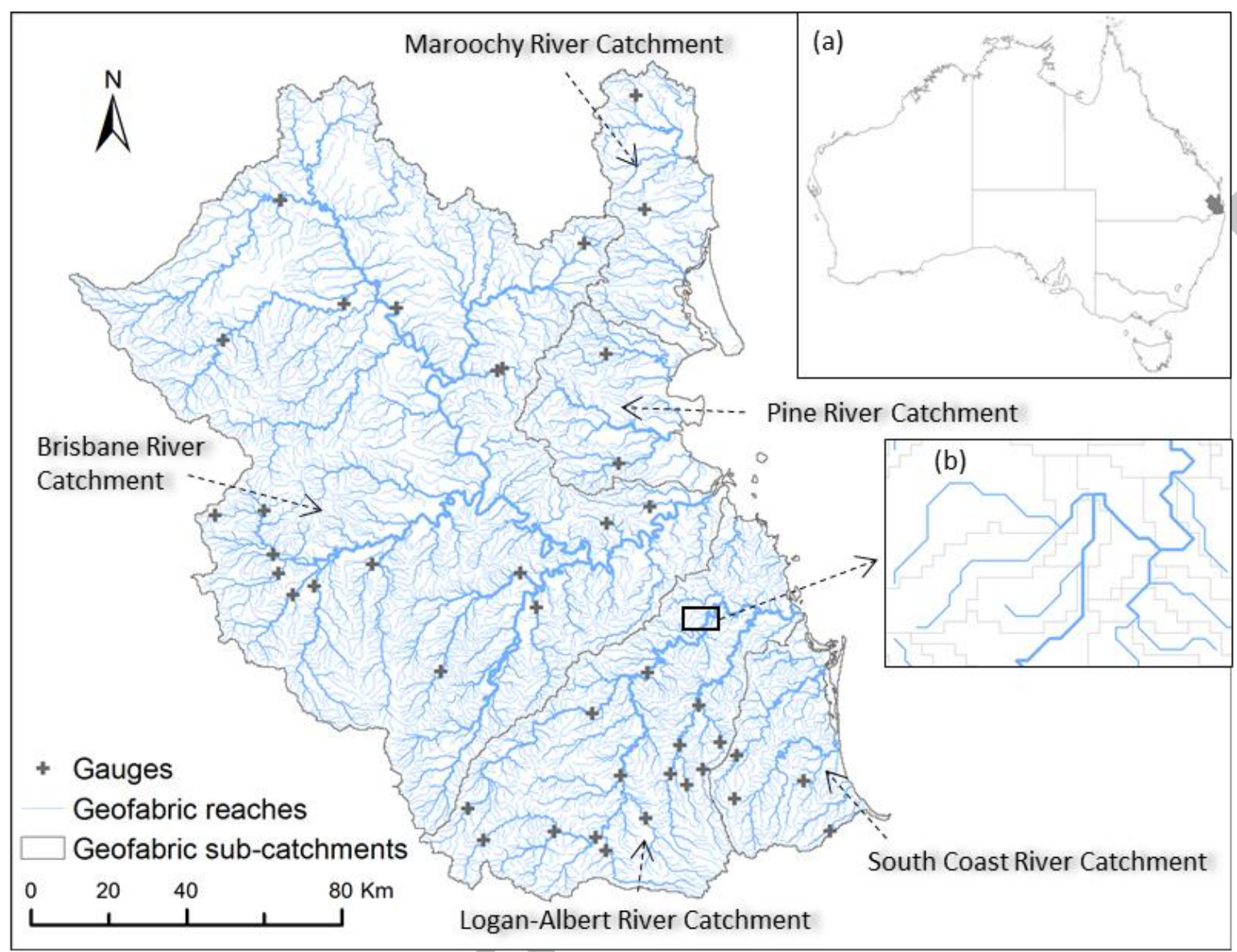

Fig.1 Geofabric river network and catchments in south-eastern Queensland and the locations of 43

selected gauges within SEQ. Inset (a) shows the relative location of SEQ in Australia and inset (b) indicates Geofabric stream segments and associated sub-catchments. 


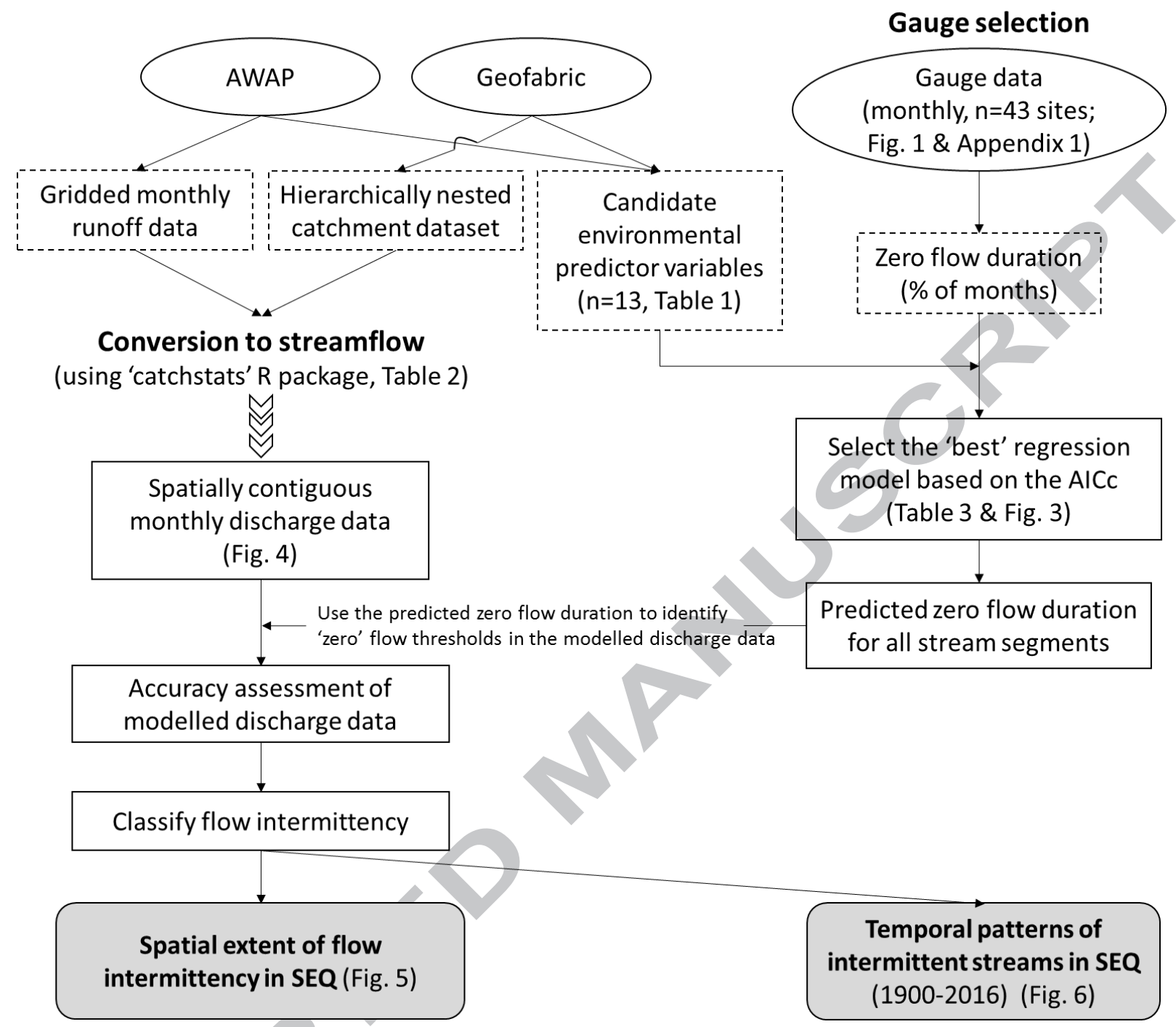

Fig. 2 Flow diagram of analysis. We collected or calculated 13 candidate environmental predictor variables from AWAP or Geofabric datasets, and calculated zero flow duration (\% of months with zero flow) with stream flow data from selected 43 gauge stations across SEQ. We developed a predictive model relating zero flow duration to environmental predictor variables and then predicted zero flow duration for all stream segments based on spatial data of the predictor variables. We aggregated gridded monthly runoff data with a hierarchically nested catchment dataset to simulate discharge throughout river networks from 1900 to 2016 . We then used the predicted zero flow duration from the regression model to estimate 'zero' flow thresholds in the modelled discharge data at all stream segments by assuming that each stream segment has the same zero flow duration as predicted. Finally, based on modelled discharge data and identified actual zero flow 
thresholds, we calculated the mean number of months per year with zero flow across $1900-2016$ to identify the spatial extent of flow intermittency in south-eastern Queensland (SEQ). We also classified flow intermittency annually for all streams in SEQ to quantify the temporal patterns of flow intermittency.

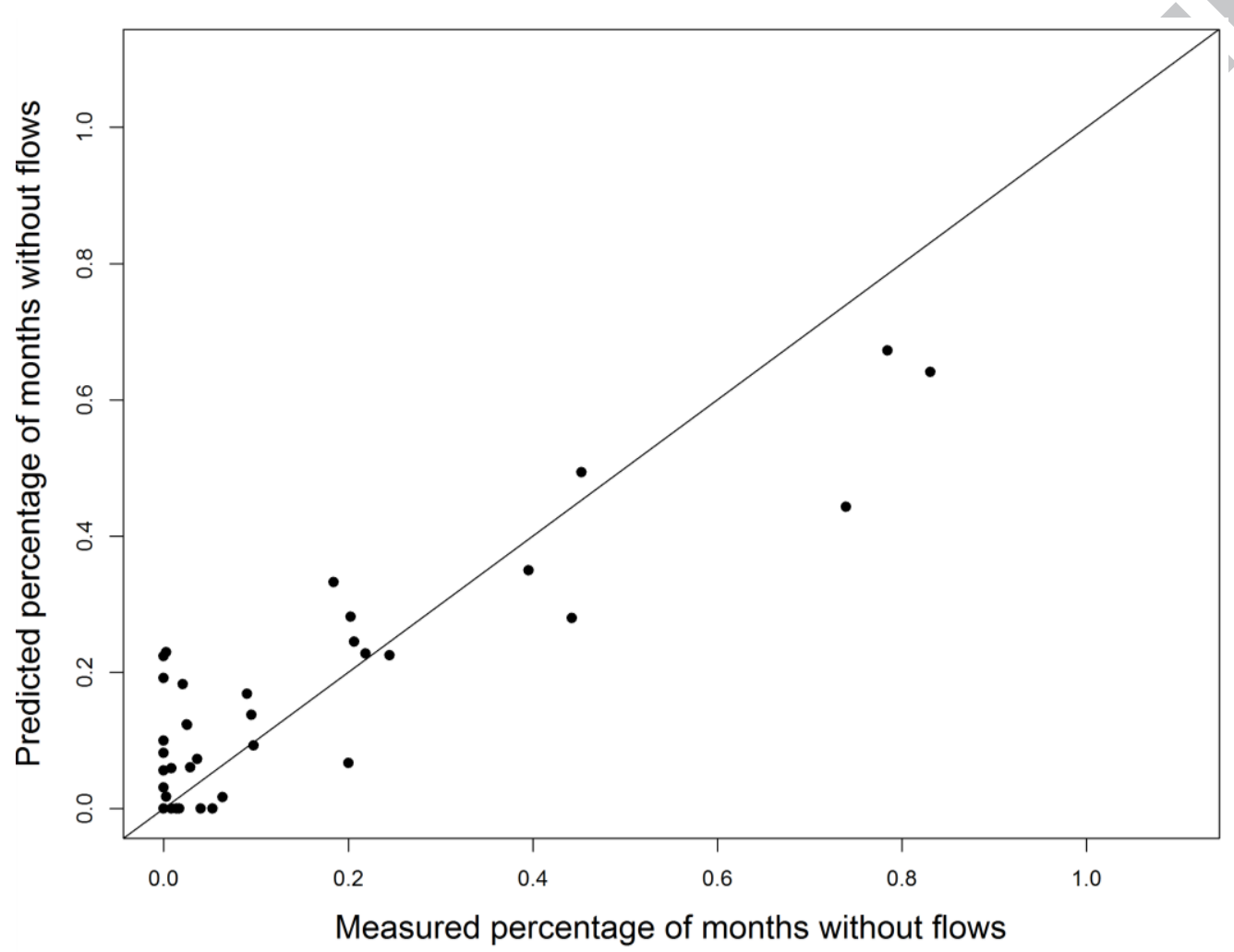

Fig. 3 Predicted vs, measured percentage of months without flows. The solid line represents the function of $y=x$. 

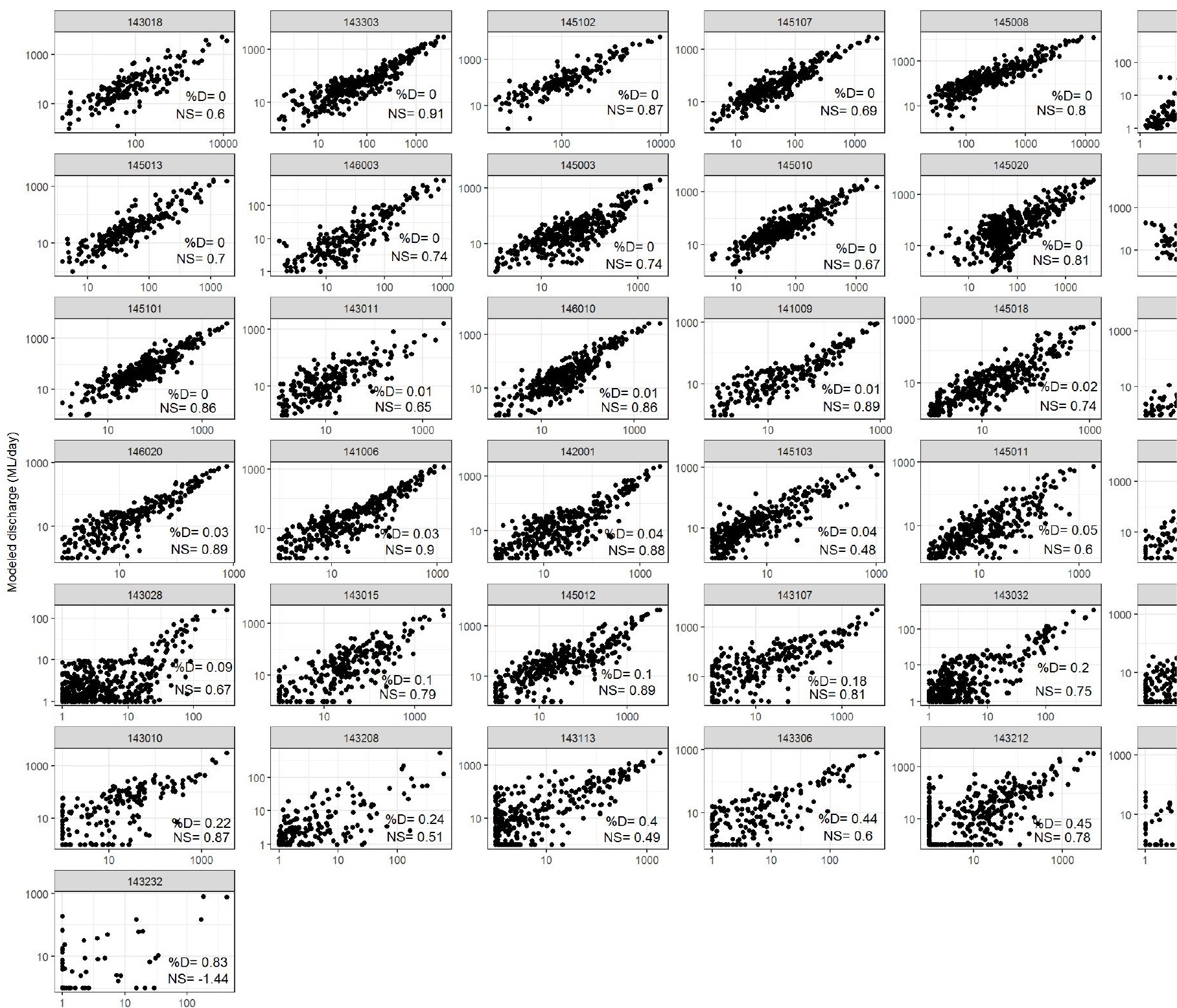

if
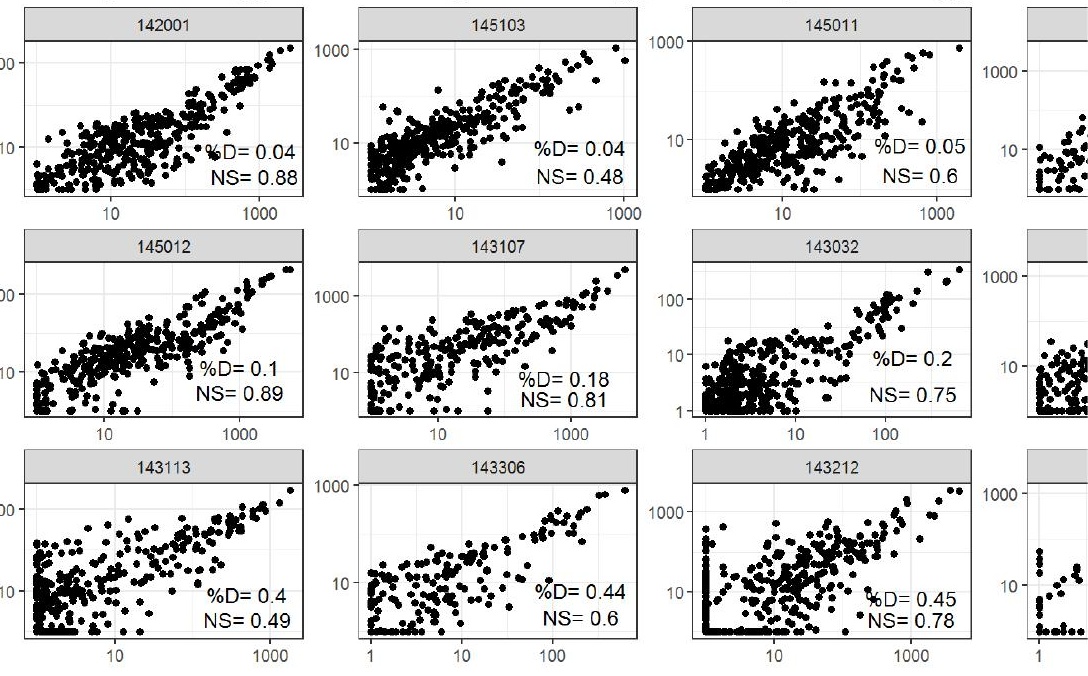

Measured discharge (ML/day)

Fig. 4 Scatter plots of the relationship between measured and modelled (truncated) discharge for

each gauge station, arranged in order of increasing percentage of months of zero flow. The

percentage of months of zero flow and Nash-Sutcliffe coefficient are presented in each panel as "\%D"

and "NS", respectively. The $x$ and $y$ axes are log transformed (i.e. $\log 10(x+1))$ for better

interpretation. 

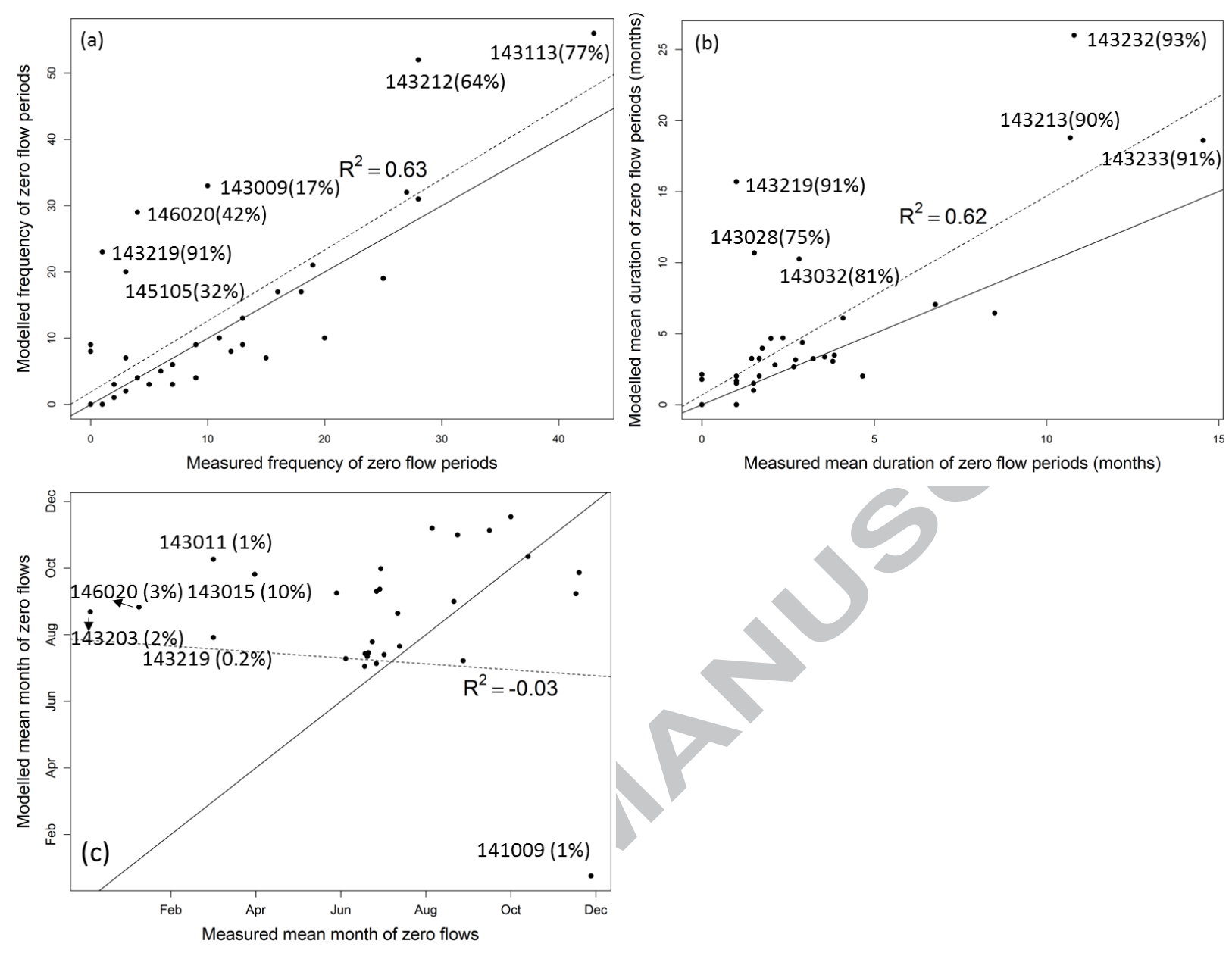

Fig. 5 Scatter plot of the relationships between measured and modelled frequency of zero flow periods (a), between measured and modelled mean duration of zero flow periods (b) and between measured and modelled mean month of zero flows (c). Outlier dots on all panels are presented with gauge number and its associated percent of months without flows in parentheses. The solid and dashed lines represent the function of $y=x$ and the regression line. $R^{2}$ value is also presented with the regression line. 


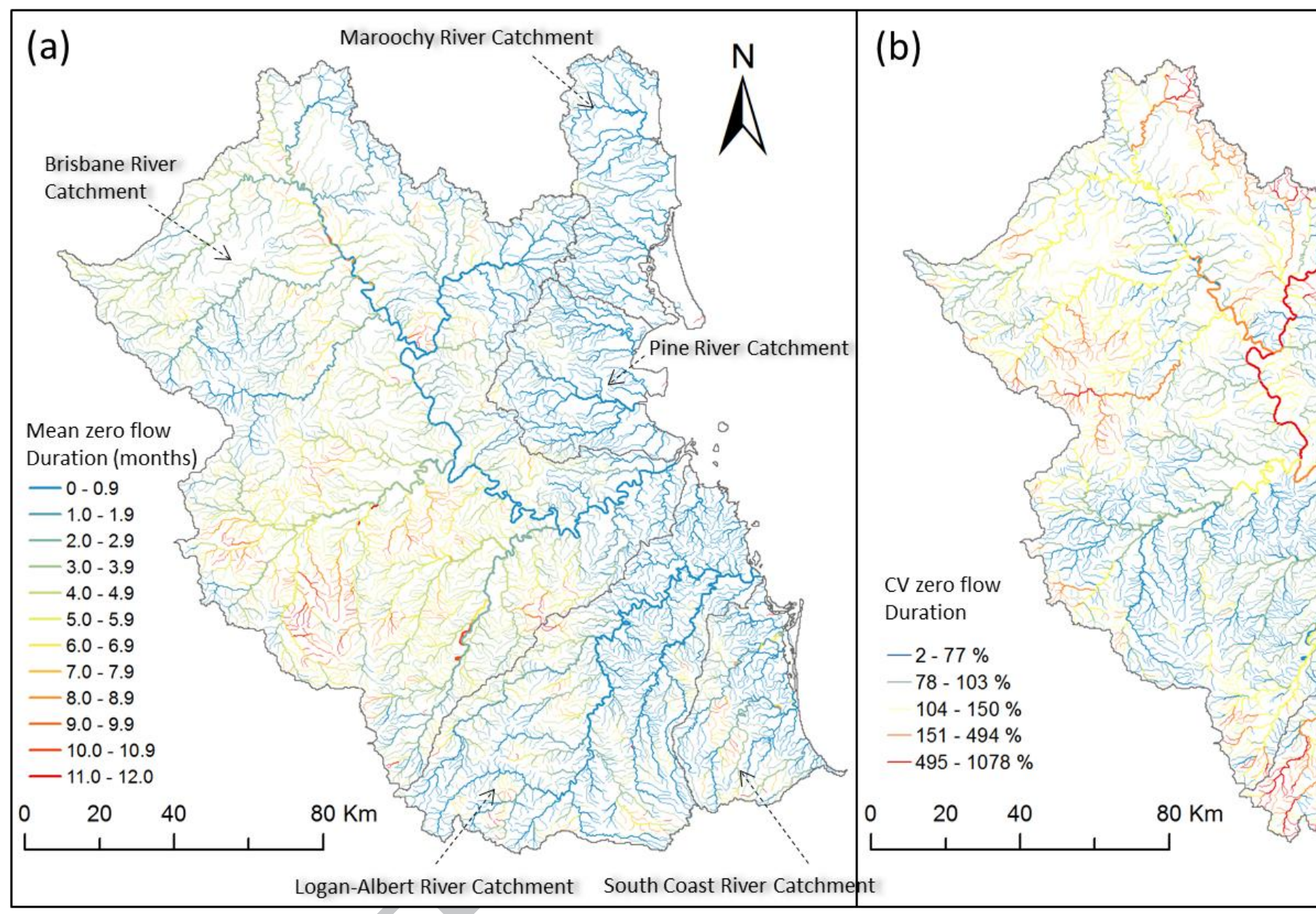

Fig. 6 The spatial extent of flow intermittency presented by (a) mean zero flow duration per year across 1900-2016 and (b) its coefficient of variation (CV). 

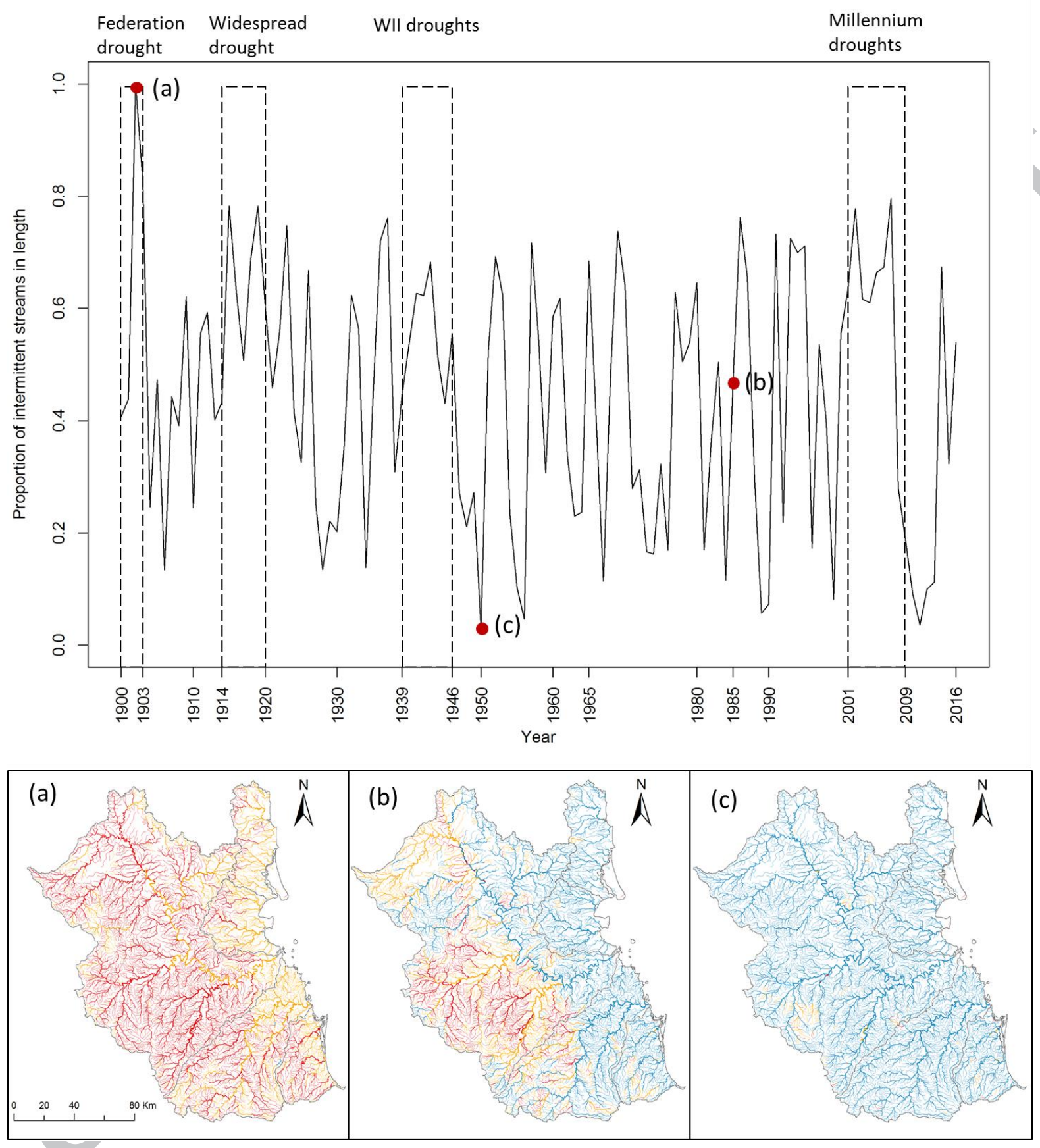

Fig. 7 The inter-annual variation of the proportion of intermittent (weakly and strongly intermittent) streams in length across SEQ. Four significant droughts in Australia were also presented as dotted rectangle, of which the width denote the duration of the drought. Insets demonstrated the specific distribution of intermittent streams in the driest year of 1902 (a), the average (median) year of 1986 (b) and the wettest year of 1950 (c) during the period of 1900-2016, respectively. Streams are colour-coded according to the classification of flow intermittency: perennial (blue) $=$ cease flowing 
$<10 \%$ of the year ( 0 - 1 months), weakly intermittent (yellow) = cease flowing $10-70 \%$ of the year $(2-$ 8 months), strongly intermittent (red) = cease flowing $>70 \%$ of the year (>8 months).

Table 1. Environmental predictor variables included in the regression analyses

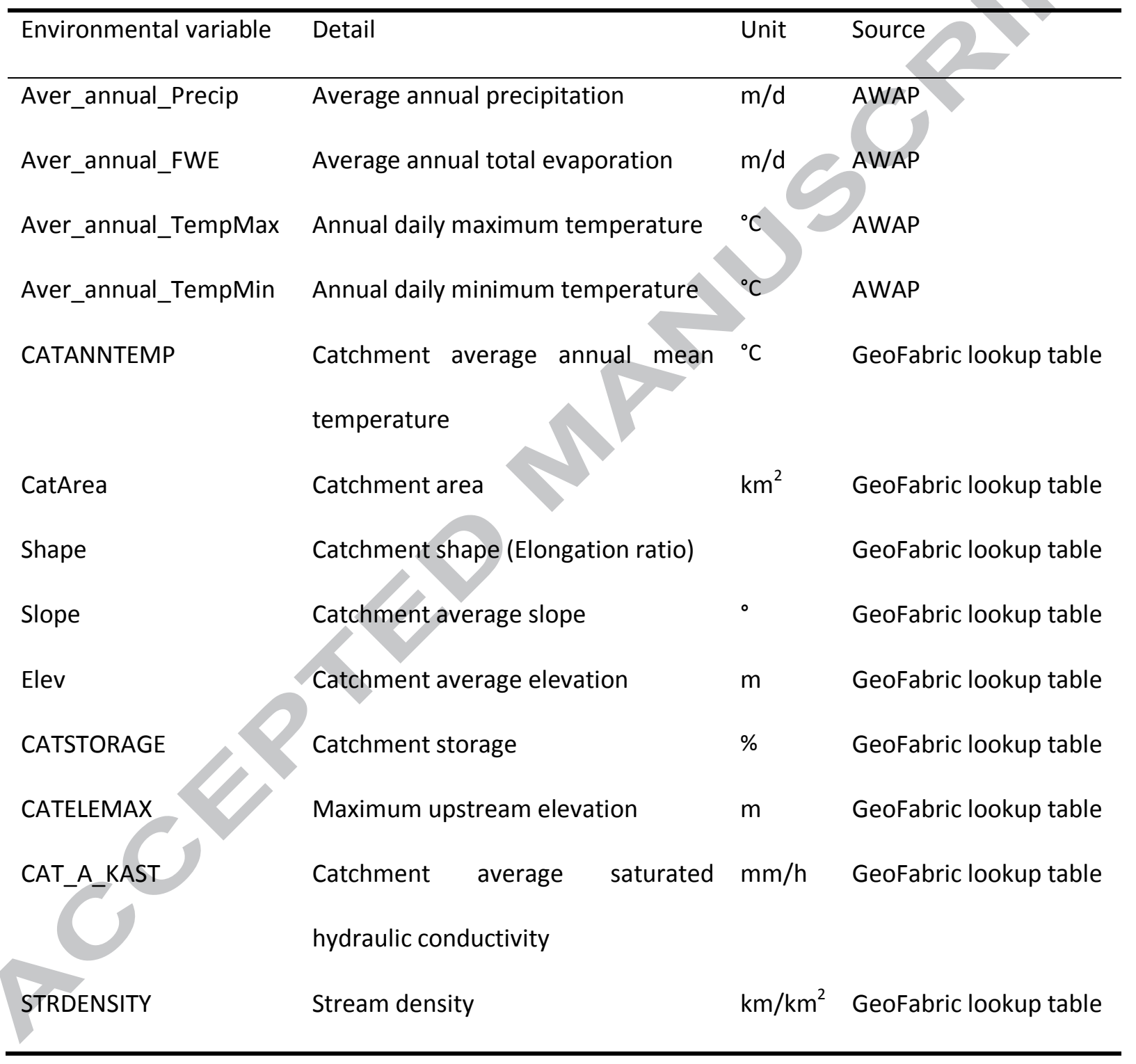

Table 2. Names and descriptions of the four functions in the package "catchstats" that were used in the conversion process. Bold functions are ones that have been updated into a parallel processing version. 


\begin{tabular}{ll}
\hline Function name & Description \\
\hline download_awap & Automatically downloads the water balance data from the AWAP website \\
stack_awap_cl & Builds a raster stack from AWAP grids for use in further analysis \\
extractRasterPoly_cl & Extracts water balance data from the raster stack \\
aggRasterPoly & Accumulates water balance data in each sub-catchment based on their \\
& longitudinal relationship
\end{tabular}

Table 3. Results of the 'best' regression model in which the percentage of months with zero flows was modelled as a function of environmental covariates shown in the first column. The standardised model coefficients and the estimated P-values for each regression parameter are also shown.

\begin{tabular}{llc}
\hline Covariate & Standardised model coefficient & P-value \\
\hline Aver_annual_TempMax & 1.86 & 0.00 \\
Log_CatArea & -0.25 & 0.01 \\
Log_Slope & 0.74 & 0.00 \\
Elev & 0.88 & 0.00 \\
CAT_A_KAST & 0.27 & 0.01 \\
\hline
\end{tabular}

\section{Highlights}

- An approach to quantifying spatial and temporal patterns of flow intermittency.

- Monthly discharge was modelled throughout river networks for $>100$ year time series.

- Appropriate zero flow thresholds were identified to indicate zero flow months.

- Flow intermittency prevailed in the majority of streams across the study area. 
- Over the past century studied streams had different degrees of flow intermittency. 


\section{Accepted Manuscript}

Research papers

Quantifying spatial and temporal patterns of flow intermittency using spatially contiguous runoff data

Songyan Yu (于松延), Nick R. Bond, Stuart E. Bunn, Zongxue Xu, Mark J.

Kennard

PII:

S0022-1694(18)30175-6

DOI: https://doi.org/10.1016/j.jhydrol.2018.03.009

Reference:

HYDROL 22642

To appear in:

Journal of Hydrology

Received Date: 3 November 2017

Revised Date: $\quad 18$ February 2018

Accepted Date: $\quad 4$ March 2018

Please cite this article as: Yu (于松延), S., Bond, N.R., Bunn, S.E., Xu, Z., Kennard, M.J., Quantifying spatial and temporal patterns of flow intermittency using spatially contiguous runoff data, Journal of Hydrology (2018), doi: https://doi.org/10.1016/j.jhydrol.2018.03.009

This is a PDF file of an unedited manuscript that has been accepted for publication. As a service to our customers we are providing this early version of the manuscript. The manuscript will undergo copyediting, typesetting, and review of the resulting proof before it is published in its final form. Please note that during the production process errors may be discovered which could affect the content, and all legal disclaimers that apply to the journal pertain. 